\title{
Investigation into impacts of land-use changes on floods in the upper Huaihe River basin, China
}

\author{
M. Yu ${ }^{1,2}$, Q. Li ${ }^{1,2}$, G. Lu' ${ }^{1}, \mathbf{H}$. Wang $^{3}$, and P. $\mathbf{L i}^{4}$ \\ ${ }^{1}$ College of Hydrology and Water Resources, Hohai University, Nanjing 210098, China \\ ${ }^{2}$ Center for International River Research, School of Business, Hohai University, Nanjing 210098, China \\ ${ }^{3}$ Xinyang Hydrology and Water Resources Survey Bureau, Xinyang, China \\ ${ }^{4}$ Henan Hydrology and Water Resources Survey Bureau, Zhengzhou, China
}

Correspondence to: M. Yu (meixiuyu1985@gmail.com)

Received: 10 April 2015 - Accepted: 10 April 2015 - Published: 11 June 2015

\begin{abstract}
To investigate the agricultural land-use change on flood regime, the upper Huaihe River basin above the Dapoling station was selected as the case study site. Based on topography, land-use, hydrological and meteorological data in 1990s and 2010s, the improved distributed Xinanjiang model, with potential evapotranspiration being computed by coupling a dual-source evapotranspiration model with a simplified plant growth model, was adopted to simulate the daily and hourly rainfall-runoff processes over 1990s and 2010s, and then the effects of land-use change on flood volume, flood peak, occurring time of flood peak, the percentage of surface runoff component were investigated respectively. The results was interesting and indicated that impacts of land-use change on flood characteristics varied significantly with land-use types. The outputs could provide valuable references for flood risk management and water resources management in the Huaihe River basin.
\end{abstract}

\section{Introduction}

In the last decades many inundations have occurred in China causing huge loss of human lives and financial damages, which have been aggravated by the intense urbanization and deforestation of flood prone areas.The impact of land use changes on storm runoff generation is currently receiving considerable public attention. It is recognized that there is an impact of land use on hydrology and flood response, however the links between land use change and flooding are still not very clear. The land use and flooding research mainly focused on the effects of urbanization (Suriya and Mudgal, 2012) and deforestation (Green and Alila, 2012), but lacking comprehensive concerns that the effects of agricultural intensification and the impact of land use practices and land management on the risk of flooding. To investigate the agricultural land-use change on flood regime, the upper Huaihe River basin, with a history of flooding over many centuries, above the Dapoling station was selected as the case study site, where the land-use was dominated by the agricultural land-use and it changed significantly in recent decades (Cai et al., 2012). Based on the topography, land-use, hydrologi- cal and meteorological data in 1990s and 2010s, the gridded Xinanjiang model (XAJ) was adopted to simulate the flood processes under different land-use patterns.

\section{Model development}

In the paper, an improved gridded XAJ model was selected for the hydrological process simulation. Since the evapotranspiration is a critical variable in determination of local water resources available, reliable estimates of evapotranspiration is essential for the improvement of hydrological simulations. In classic XAJ model (Zhao, 1992), evapotranspiration is always simulated in an empirical or conceptual way or mostly in a lumped way. In the study, the distributed dualsource evapotranspiration model (DESM), considering the soil potential evaporation, vegetation potential evaporation, and evaporation of intercepted rainfall together was adopted to calculate the evapotranspiration as one of the inputs of the gridded XAJ model. However, one of the important input - leaf area index (LAI) of the DSEM, was often estimated by using remotely sensed data on a monthly scale, which 


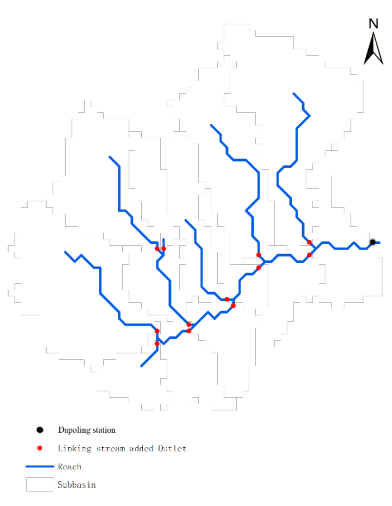

$\AA^{N}$

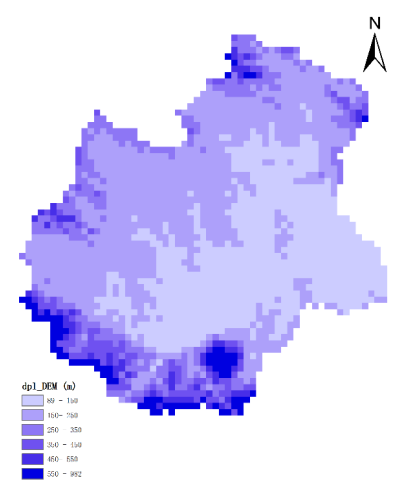

Figure 1. Sketch map and DEM of the upper Huaihe River above the Dapoling station.

could not reflect the actual dynamic evolution of plants. A simplified plant growth model, being capable of calculating the daily LAI, was coupled with the DESM, which not only could capture the actual dynamic evapotranspiration evolution of vegetation, but also reflect the evapotranspiration differences of vegetation types for different land-uses. Thus, a semi-distributed XAJ model coupled with the modified DESM was used to simulate water-balance process and flood process. For detailed description of the XAJ model, it can be referred to Zhao (1992).

\section{Model application}

\subsection{Case study site}

The Huaihe River Basin is one of seven major river basins in China, and lies in the warm temperature semi-humid monsoon region, which is a transition zone between the climates of North and South China, with a history of flooding over many centuries. With intensified human activities including land-use change in the basin, which has China's highest population density (662 persons per km2), the rainfall-runoff relationship has been altered in terms of flood frequency and magnitude. This paper aims to evaluate impacts of landuse change in the upper Huaihe river basin above Dapoling gauge station on its floods. The study area has a catchment area of $1413 \mathrm{~km}^{2}$, and was divided into grids with a size of $0.873 \mathrm{~km} \times 0.873 \mathrm{~km}$ to consider the spatial unevenness of precipitation and underlying conditions.

\subsection{Data collection and processing}

\subsubsection{Topography data}

The digital elevation model (DEM) data was downloaded from the Global Land One kilometer Base Elevation database with a spatial resolution of $0.873 \mathrm{~km} \times 0.873 \mathrm{~km}$, and the Archydro tool was used to obtain the river net and catchment boundary (Fig. 1).

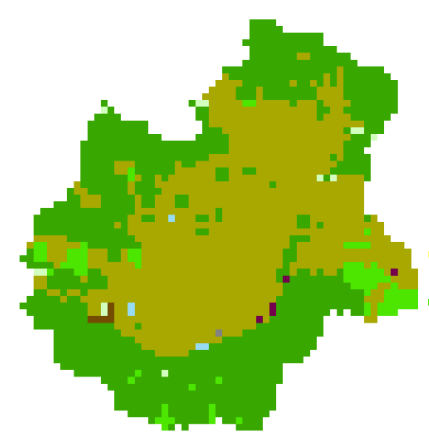

(a) $1980 \mathrm{~s}$

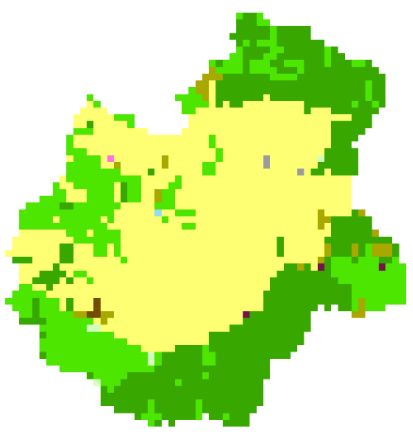

(b) $1990 \mathrm{~s}$



(c) $2000 \mathrm{~s}$

Figure 2. Land-uses in three-phrases in the upper Huaihe River above the Dapoling station.

\subsubsection{Land-use data}

The land-use maps of 1980s, 1990s and 2000s for Dapoling subbasin were collected from the Chinese Academy of Science (see Fig. 2). It can be seen that the spatial distribution of land-use in 1980s and 2000s was very similar, i.e. being dominated by the dryland in the middle of the basin both in 1980s and 2000s; in contrast, paddy land was the main land-use in 1990s. Since the land-use patterns in the upper Huaihe River basin above the Dapoling station were similar in 1980s and 2000s, the land-use maps in 1990s and 2000s were used to investigate the impact of land-use change on the flood regime in the upper Huaihe River basin above Dapoling station.

\subsubsection{Hydrological data}

The daily precipitation at 13 stations and daily flow discharge at Dapoling hydrological station during 1990-2010 were collected from the Huaihe River Water Resources Commission for the water-balance simulation of the improved the Xinanjiang model, while hourly precipitation at 13 stations and hourly flow discharge at Dapoling station during 1990-2010 were obtained for the flood process simulation. 
Table 1. Calibrated parameters for the daily Xinanjiang model in Dapoling sub-basin.

\begin{tabular}{lrrr}
\hline Parameters & Meaning of parameters & $1990 \mathrm{~s}$ & $2000 \mathrm{~s}$ \\
\hline UM & areal mean tension water capacity in the upper layer (mm) & 20 & 20 \\
LM & areal mean tension water capacity in the lower layer (mm) & 60 & 60 \\
$C$ & coefficient of deel evapotranspiration & 0.1 & 0.1 \\
WM & areal mean tension water capacityr (mm) & 120 & 120 \\
$B$ & exponent of the tension water capacity curve & 0.4 & 0.4 \\
IM & ratio of the impervious to the total area of the basin & 0.001 & 0.001 \\
SM & areal mean of the free water capacity of the surface soil layer (mm) & 39.54 & 25.9 \\
EX & exponent of the freewater capacity curve & 1.2 & 1.2 \\
KG & outflow coefficient of the freewater storage to groundwater relationship & 0.45 & 0.45 \\
CS & recession constant of surface water storage & 0.465 & 0.3 \\
CI & recession constant of interflow water storage & 0.686 & 0.686 \\
GG & recession constant of groundwater storage & 0.994 & 0.963 \\
$L$ & & lag time (h) & 1 \\
XE & parameter of the Muskingum method & 0.49 & 0.49 \\
\hline
\end{tabular}

Table 2. Statistics of daily calibrated and validated results for Dapoling sub-basin in 1990s.

\begin{tabular}{crrrrrrr}
\hline Periods & year & $P(\mathrm{~mm})$ & $R_{\mathrm{O}}(\mathrm{mm})$ & $R_{\mathrm{c}}(\mathrm{mm})$ & $\mathrm{AE}(\mathrm{mm})$ & $\mathrm{RE}(\%)$ & $\mathrm{DC}$ \\
\hline Calibration period & 1990 & 860 & 257.6 & 275.8 & 18.2 & 7.1 & 0.79 \\
& 1991 & 1152 & 534.6 & 525 & -9.6 & -1.8 & 0.93 \\
& 1992 & 667 & 113.1 & 110 & -3.1 & -2.7 & 0.71 \\
& 1993 & 811 & 184.2 & 200.1 & 16 & 8.7 & 0.75 \\
& 1994 & 802 & 142.8 & 133.2 & -9.6 & -6.7 & 0.55 \\
& 1995 & 819 & 188.3 & 193.4 & 5.1 & 2.7 & 0.72 \\
& 1996 & 991 & 416.1 & 399 & -17 & -4.1 & 0.68 \\
\hline Validation period & 1997 & 730 & 166.8 & 171.7 & 4.9 & 2.9 & 0.73 \\
& 1998 & 1250 & 640.9 & 671.4 & 30.5 & 4.8 & 0.91 \\
& 1999 & 595 & 94 & 89.5 & -4.5 & -4.8 & 0.63 \\
\hline
\end{tabular}

Notes: I and II for calibration period and validation period respectively. $P$ for precipitation, $R_{\mathrm{O}}$ for observed runoff, $R_{\mathrm{c}}$ for calculated runoff, $\mathrm{AE}$ for abs error, $\mathrm{RE}$ for relative error, $\mathrm{DC}$ for determined coefficient, $\mathrm{AE}$ Peak for absolute error of flood peak, $\mathrm{RE}_{\text {Peak }}$ for relative error of flood peak, $\mathrm{Lag}_{\text {peak }}$ for flood peak lag time.

\subsubsection{Meteorological data}

The meteorological data, including daily temperature, solar net radiation, humidity, wind speed, etc. at six weather stations in or neighboring the study area during 1990-2010 were collected from the China Meteorological Administration (CMA).

\subsection{Model calibration and validation}

\subsubsection{Water-balance Model}

The daily XAJ model was calibrated and validated by the use of observed daily flow, precipitation, and meteorological data in 1990s and 2000s. The calibration periods for two phases (1990s and 2000s) were 1990-1996 and 2000-2006 respectively, and their validation periods were 1997-1999 and 2007-2010 correspondingly (Tables 1-3). The simulation performance disclosed that the daily XAJ model can be simulated with satisfactory accuracy, with the determined co- efficient values (DC) both for calibration and validation periods were more than 0.73 in 1990s and 0.93 in 2000s, and the relative error values (RE) both for calibration and validation periods were generally less than $10 \%$ in 1990s and 2000s. The above suggested that parameters of the daily XAJ model could be used as the initial conditions for the flood simulation model.

\subsubsection{Flood simulation model}

The hourly XAJ model was calibrated and validated by the use of observed hourly flow, precipitation in 1990s and 2000s respectively (Tables 4-6). In 1990s, the DC value was higher than 0.93 , RE less than $10 \%, \mathrm{RE}_{\text {peak }}$ less than $20 \%$ generally (Table 5) both for calibration and validation periods; while in 2000 s, the DC value was higher than 0.73 , RE less than $10 \%$, $\mathrm{RE}_{\text {peak }}$ less than $20 \%$ generally (Table 6) both for calibration and validation periods. It demonstrated that the hourly XAJ model performed very well in the flood process simulation 
Table 3. Statistics of daily calibrated and validated results for Dapoling sub-basin in 2000s.

\begin{tabular}{crrrrrrr}
\hline Periods & year & $P(\mathrm{~mm})$ & $R_{\mathrm{O}}(\mathrm{mm})$ & $R_{\mathrm{c}}(\mathrm{mm})$ & $\mathrm{AE}(\mathrm{mm})$ & $\mathrm{RE}(\%)$ & $\mathrm{DC}$ \\
\hline Calibration period & 2000 & 1305 & 636.7 & 579.1 & -57.6 & -9 & 0.830 \\
& 2001 & 578 & 111.1 & 116.1 & 5.1 & 4.6 & -0.380 \\
& 2002 & 957 & 307.8 & 339.3 & 31.5 & 10.2 & 0.900 \\
& 2003 & 1113 & 519.7 & 491 & -28.8 & -5.5 & 0.910 \\
& 2004 & 866 & 228.6 & 234.3 & 5.7 & 2.5 & 0.830 \\
& 2005 & 1417 & 734.5 & 694.4 & -40.1 & -5.5 & 0.920 \\
& 2006 & 875 & 236.9 & 220.3 & -16.6 & -7 & 0.760 \\
\hline Validation period & 2007 & 1125 & 464.2 & 476.2 & 11.9 & 2.6 & 0.920 \\
& 2008 & 1081 & 463.2 & 460.7 & -2.5 & -0.5 & 0.960 \\
& 2009 & 841 & 252.4 & 232.7 & -19.6 & -7.8 & 0.950 \\
& 2010 & 963 & 349.2 & 318.9 & -30.3 & -8.7 & 0.630 \\
\hline
\end{tabular}

Table 4. Calibrated parameters for the hourly Xinanjiang model in Dapoling sub-basin.

\begin{tabular}{llrr}
\hline Parameters & Meaning of parameters & $1990 \mathrm{~s}$ & $2000 \mathrm{~s}$ \\
\hline UM & areal mean tension water capacity in the upper layer (mm) & 20 & 20 \\
LM & areal mean tension water capacity in the lower layer (mm) & 60 & 60 \\
$C$ & coefficient of deel evapotranspiration & 0.1 & 0.1 \\
WM & areal mean tension water capacityr (mm) & 120 & 120 \\
$B$ & exponent of the tension water capacity curve & 0.4 & 0.4 \\
IM & ratio of the impervious to the total area of the basin & 0.001 & 0.001 \\
SM & areal mean of the free water capacity of the surface soil layer (mm) & 40 & 40 \\
EX & exponent of the freewater capacity curve & 1.2 & 1.2 \\
KG & outflow coefficient of the freewater storage to groundwater relationship & 0.45 & 0.45 \\
CS & recession constant of surface water storage & 0.85 & 0.8 \\
CI & recession constant of interflow water storage & 0.686 & 0.683 \\
GG & recession constant of groundwater storage & 0.997 & 0.995 \\
$L$ & lag time (h) & 3 & 4 \\
XE & parameter of the Muskingum method & 0.49 & 0.49 \\
\hline
\end{tabular}

and parameterization schemes of hourly XAJ model could be further used to investigate the impact of the land-use change on the flood characteristics in the Dapoling basin in the upper Huaihe River basin.

\subsection{Flood events simulation under different land-use patterns}

Twelve floods (six in 1990s and six in 2000s) were selected to simulate the effect of land-use change on the flood volume, flood peak, flood peak occurring time, and the ratio of surface runoff to the total runoff by using different parameterization schemes (see Table 4). It is worth noting that same precipitation process was applied during the simulation of the same flood event. To save the space, only two flood process was displayed (Figs. 3-4).

\section{Results and discussion}

\subsection{Impacts of land-use changes on flood volume}

Figure 3 showed the temporal variations of hourly flow under different land-use patterns. From Fig. 3 it can be found that compared with the flood process by using the parameterization scheme of 1990s, the corresponding flood process by using the parameterization scheme of 2000 s became more uneven. It disclosed that the temporal distribution of flood was changed apparently when the land-use changed from paddy land to dryland. Flood volume accumulation calculation also revealed that the flood volume increased significantly from $8.143 \times 10^{7} \mathrm{~m}^{3}$ to $8.413 \times 10^{7} \mathrm{~m}^{3}$ for flood $\# 19960628$, and from $1.418 \times 10^{8} \mathrm{~m}^{3}$ to $1.452 \times 10^{8} \mathrm{~m}^{3}$ for flood \#20050828 correspondingly from 1990 s to 2000 s, with the increased percentage of 3.32 and $2.38 \%$ respectively. Clearly, it can be concluded that the land-use changing from paddy land to dryland will increase flood volume significantly under the same precipitation condition. 
Table 5. Statistics of hourly calibrated and validated results for Dapoling sub-basin in 1990s.

\begin{tabular}{crrrrrrrrrr}
\hline Period & Flood NO. & $P(\mathrm{~mm})$ & $R_{\mathrm{O}}(\mathrm{mm})$ & $R_{\mathrm{c}}(\mathrm{mm})$ & $\mathrm{AE}(\mathrm{mm})$ & $\mathrm{RE}(\%)$ & $\mathrm{DC}$ & $\mathrm{AE}_{\text {Peak }}\left(\mathrm{m}^{3} \mathrm{~s}^{-1}\right)$ & $\mathrm{RE}_{\text {Peak }}(\%)$ & $\mathrm{Lag}_{\text {peak }}(\mathrm{h})$ \\
\hline \multirow{2}{*}{ I } & 12 Jun 1991 & 114.8 & 85.6 & 82.5 & -3.1 & -3.6 & 0.96 & -118.9 & -8.4 & -1 \\
& 5 Jul 1991 & 113.6 & 66.4 & 67 & 0.6 & 0.9 & 0.94 & 270.5 & 17.6 & -1 \\
& 5 Aug 1991 & 183.0 & 104.7 & 109.2 & 4.5 & 4.3 & 0.95 & 65.2 & 4.2 & 2 \\
& 28 Jun 1996 & 139.9 & 46.1 & 47.4 & 1.3 & 2.7 & 0.97 & 32.6 & 2.1 & -1 \\
& 7 Jul 1996 & 92.3 & 60 & 57.7 & -2.3 & -3.8 & 0.80 & -94.4 & -10.1 & 0 \\
& 16 Jul 1997 & 159.1 & 39.5 & 43.2 & 3.7 & 9.5 & 0.94 & 170.2 & 13.9 & 0 \\
\hline \multirow{2}{*}{ II } & 29 Jun 1998 & 171.1 & 68 & 74.1 & 6.2 & 9.1 & 0.93 & 10.5 & 0.9 & -1 \\
& 2 Aug 1998 & 161.3 & 78.2 & 80.8 & 2.6 & 3.3 & 0.96 & 227.7 & 13.2 & -1 \\
& 13 Aug 1998 & 95.2 & 35.8 & 34.2 & -1.7 & -4.7 & 0.97 & 49.4 & 4.6 & 0 \\
\hline
\end{tabular}

Table 6. Statistics of hourly calibrated and validated results for Dapoling sub-basin in 2000s.

\begin{tabular}{crrrrrrrrrr}
\hline Period & Flood NO. & $P(\mathrm{~mm})$ & $R_{\mathrm{O}}(\mathrm{mm})$ & $R_{\mathrm{C}}(\mathrm{mm})$ & $\mathrm{AE}(\mathrm{mm})$ & $\mathrm{RE}(\%)$ & $\mathrm{DC}$ & $\mathrm{AE}_{\text {Peak }}\left(\mathrm{m}^{3} \mathrm{~s}^{-1}\right)$ & $\mathrm{RE}_{\text {Peak }}(\%)$ & Lag $_{\text {peak }}(\mathrm{h})$ \\
\hline \multirow{2}{*}{ I } & 3 Jun 2000 & 209.4 & 80.3 & 87.6 & 7.3 & 9.1 & 0.95 & -287.0 & -14.7 & 0 \\
& 22 Jun 2002 & 131.9 & 80.1 & 76.7 & -3.4 & -4.2 & 0.96 & 360.6 & 18.5 & -1 \\
& 30 Jun 2003 & 140.6 & 103.8 & 112.7 & 8.9 & 8.6 & 0.91 & -14.3 & -1.6 & 22 \\
& 20 Jul 2003 & 67.5 & 56.9 & 52.2 & -4.7 & -8.2 & 0.96 & 220.1 & 20.6 & 0 \\
& 4 Aug 2004 & 84.4 & 52.3 & 47.6 & -4.7 & -9 & 0.87 & 123.4 & 15.8 & 0 \\
& 28 Aug 2005 & 130.0 & 88.4 & 84.4 & -3.9 & -4.4 & 0.97 & 170.1 & 6.6 & -1 \\
\hline \multirow{2}{*}{ II } & 3 Jul 2007 & 113.1 & 63.4 & 68.1 & 4.8 & 7.5 & 0.89 & -4.3 & -0.3 & -2 \\
& 21 Jul 2008 & 267.3 & 147.6 & 158.6 & 11 & 7.5 & 0.91 & -40.6 & -2.5 & -1 \\
& 26 Aug 2009 & 162.5 & 53.4 & 53.6 & 0.2 & 0.4 & 0.95 & 95.4 & 8.4 & -2 \\
\hline
\end{tabular}

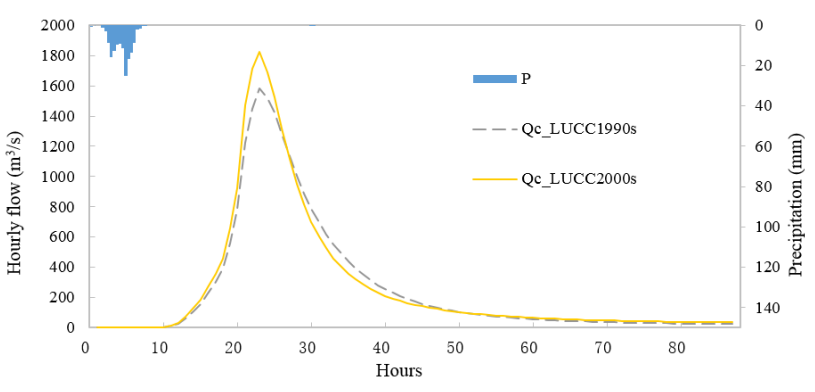

(a)\#19960628



(b)\#20050828

Figure 3. Temporal variations of hourly flow for different flood events.

\subsection{Impacts of land-use changes on flood peak}

Under the same precipitation condition, the flood process became much thinner and the flood peak became much higher (Fig. 3). From 1990s to 2000s, the flood peak increased significantly from 1582.6 to $1825.8 \mathrm{~m}^{3} \mathrm{~s}^{-1}$ with increased percentage of $15.4 \%$ for flood \#19960628, and from 2454.2 to $2750.1 \mathrm{~m}^{3} \mathrm{~s}^{-1}$ with increased percentage of $12.1 \%$ for flood \#20050828. Nevertheless, the flood peak occurring time also advanced from 0 to $3 \mathrm{~h}$ from 1990 s to 2000s. This indicated that land-use changing from paddy land to dryland will result in greater flood peak, and earlier flood peak occurring time.

\subsection{Impacts of land-use changes on percentage of surface runoff component}

Figure 4 presented the temporal variations of the percentage of surface runoff component in the upper Huaihe River basin above the Dapoling station. The percentage of surface runoff component in 2000s was generally higher than that in 1990s in earlier time of the flood process, while lower than that in 1990s in later time of the flood event. What's more, the ratio of the surface runoff in 1990s was significantly higher than that in 2000s during the peak stage of the surface runoff. Besides, it can be found that the process of the ratio of surface runoff was similar to that of the precipitation with several hours ahead of the surface runoff. The analysis above demonstrated that the land-use changing from paddy land to dryland will lead to higher surface runoff percentage of the 




(a)\#19960628

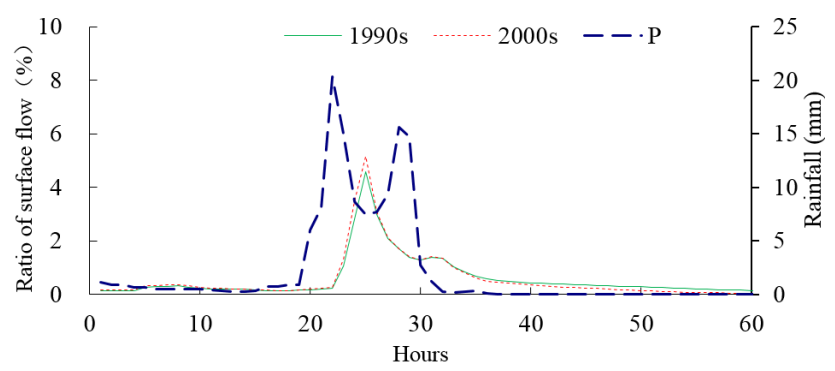

(b)\#20050828

Figure 4. Temporal variations of the percentage of surface runoff component.

total runoff during earlier time of the flood, especially in period with rapid runoff production.

\section{Conclusions}

This paper investigated the impacts of agricultural land-use changes on the flood characteristics by using the gridded XAJ model in the upper Huaihe River basin above the Dapoling station. The results revealed that: (1) the XAJ model performed very well in the water-balance simulation and flood process simulation; (2) land-use changing from paddy land to dryland will increase the flood volume and the flood peak, advance the flood peak occurring time, and lead to higher surface runoff percentage of the total runoff during earlier time of the flood.
Acknowledgements. Financial support is gratefully acknowledged from the National Science Foundation Commission under Grant No. 41171220, China, the project (2014B04314) supported by the Fundamental Research Funds for the Central Universities.

\section{References}

Cai, T., Li, Q. F., Yu, M. X., and Lu, G. B.: Investigation into the impacts of land-use change on sediment yield characteristics in the upper Huaihe River basin, China, Phys. Chem. Earth, 53-54, $1-9,2012$.

Green, P. and Alila, Y.: A paradigm shift in understanding and quantifying the effects of forest harvesting on floods in snow environments, Water Resour. Res., 48, W10503, doi:10.1029/2012WR012449, 2012.

Suriya, S. and Mudgal, B. V.: Impact of urbanization on flooding: The Thirusoolam sub watershed - A case study, J. Hydrol., 412413, 210-219, 2012.

Zhao, R. J.: The Xinanjiang model applied in China, J. Hydrol., 135, 371-381, 1992. 